Research Article

\title{
The Influence of Neck Muscle Activation on Head and Neck Injuries of Occupants in Frontal Impacts
}

\author{
Fan Li $\mathbb{D}^{1},{ }^{1}$ Ronggui Lu, ${ }^{1}$ Wei Hu, ${ }^{1}$ Honggeng Li, ${ }^{1}$ Shiping $\mathrm{Hu}^{2}{ }^{2}$ Jiangzhong $\mathrm{Hu}^{2}$ \\ Haibin Wang, ${ }^{3}$ and $\mathrm{He} \mathrm{Xie}^{3}$ \\ ${ }^{1}$ State Key Laboratory of Advanced Design Manufacturing for Vehicle Body, Hunan University, Changsha 410082, China \\ ${ }^{2}$ Xiangya Hospital of Central South University, Xiangya Hospital, Changsha 410008, China \\ ${ }^{3}$ CRRC Zhuzhou Institute Co. Ltd., Zhuzhou, China
}

Correspondence should be addressed to Fan Li; lifandudu@163.com

Received 7 December 2017; Revised 11 February 2018; Accepted 28 February 2018; Published 9 May 2018

Academic Editor: Jun Xu

Copyright ( $) 2018$ Fan Li et al. This is an open access article distributed under the Creative Commons Attribution License, which permits unrestricted use, distribution, and reproduction in any medium, provided the original work is properly cited.

\begin{abstract}
The aim of the present paper was to study the influence of neck muscle activation on head and neck injuries of vehicle occupants in frontal impacts. A mixed dummy-human finite element model was developed to simulate a frontal impact. The head-neck part of a Hybrid III dummy model was replaced by a well-validated head-neck FE model with passive and active muscle characteristics. The mixed dummy-human FE model was validated by $15 \mathrm{G}$ frontal volunteer tests conducted in the Naval Biodynamics Laboratory. The effects of neck muscle activation on the head dynamic responses and neck injuries of occupants in three frontal impact intensities, low speed $(10 \mathrm{~km} / \mathrm{h})$, medium speed $(30 \mathrm{~km} / \mathrm{h})$, and high speed $(50 \mathrm{~km} / \mathrm{h})$, were studied. The results showed that the mixed dummy-human FE model has good biofidelity. The activation of neck muscles can not only lower the head resultant acceleration under different impact intensities and the head angular acceleration in mediumand high-speed impacts, thereby reducing the risks of head injury, but also protect the neck from injury in low-speed impacts.
\end{abstract}

\section{Introduction}

Vehicle accidents kill approximately 1.25 million people each year, and another 20 to 50 million people suffer nonfatal injuries, with the costs accounting for $1-3 \%$ of the gross domestic product of most countries [1]. Head and neck injuries are the most severe injuries in vehicle accidents $[2,3]$. The study by NHTSA (National Highway Traffic Safety Administration) [4] found that nearly 15,000 passenger vehicle occupant deaths occur annually in the United States due to car accidents involving frontal crashes.

With the development of passive safety techniques, occupants are better protected during vehicle accidents. To date, however, the muscle activation behavior of occupants has not been considered in crash tests. Muscle activation plays an important role in human body function and will generate forces that affect the occupants' dynamic response upon colliding with an airbag $[5,6]$ and their biomechanical responses $[7,8]$, especially in a low-speed impact, which will increase the cervical stretch tolerance and vary the injury locations from the lower cervical spine to near the head [9]. Additionally, the stress on the upper cervical ligament in a frontal impact would be significantly reduced by the force of muscle contraction [10]. However, the injury mechanism influenced by the muscle contracting force remains unclear, especially for the injury of soft tissues in the neck. Recent studies on head and neck injuries have mostly focused on a rear-end impact, which would slow the progress of neck injury prevention. Although the observed frequency of neck injuries in a rear-end impact versus a frontal impact of comparable severity was higher [11], the effect of the muscle activation force should not be ignored for a low-speed frontal impact [12]. In a severe frontal impact, the neck will acquire an $S$ shape, as observed in rear-end impacts, leading to unclear injuries to neck tissues [13]. Thus, we need to study the muscle activation in head and neck injuries of occupants in frontal impacts. 


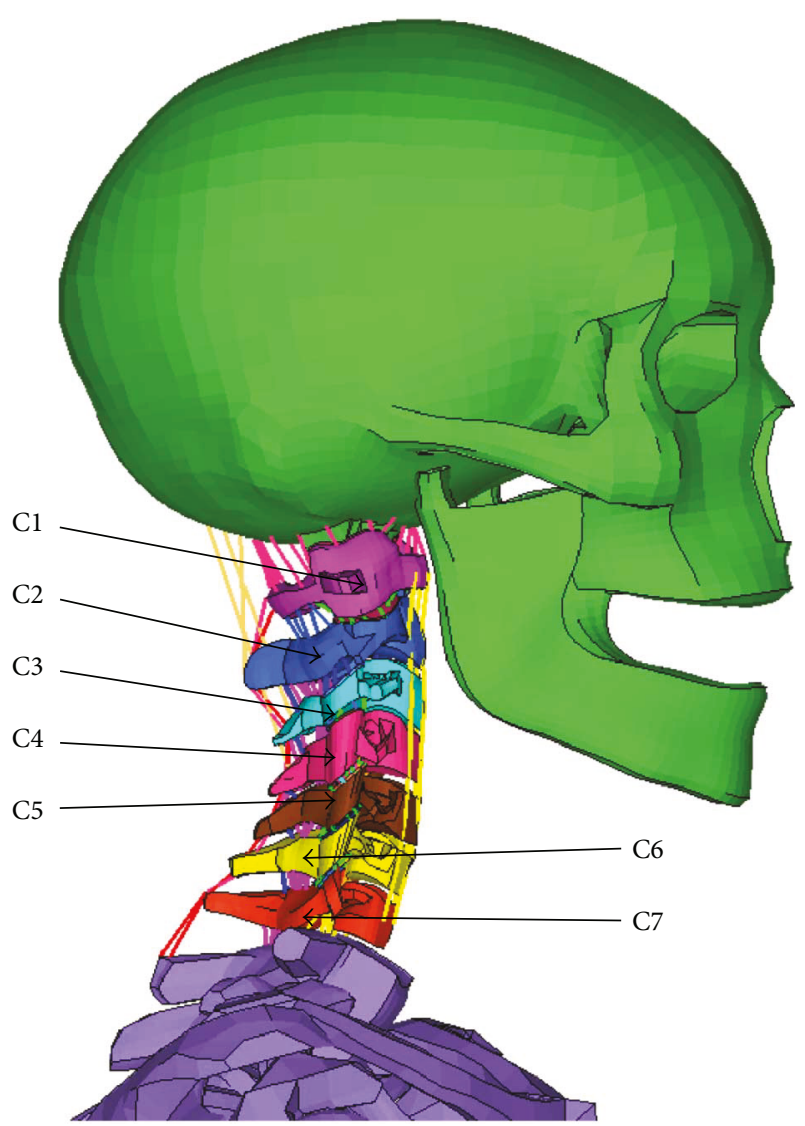

Figure 1: Basic head-neck human FE model.

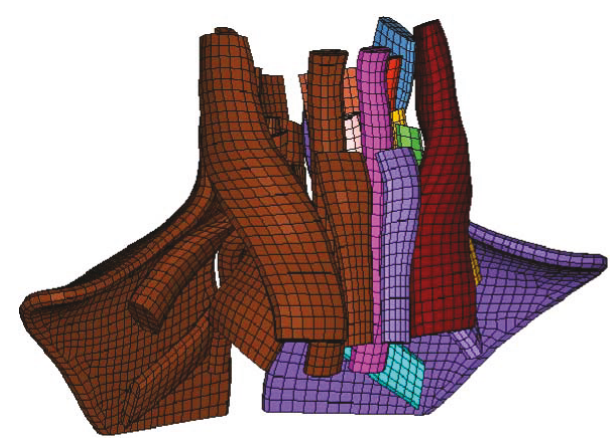

Figure 2: Neck muscle model.

Previous methods for studying the influence of muscle activation on neck injuries have many shortcomings: the mechanical dummies have lower biofidelity; PHMS (post mortem human subjects) tests cannot represent muscle activation behavior, even though they can be used to simulate a high-speed impact; and volunteer tests can only be carried out in a very low-speed impact for ethical reasons, although muscle activation can still be observed. Consequently, FE model simulation seems to be able to overcome the deficiencies of the former methods: it can easily obtain important information, including dynamic parameters and even the stress and strain at different magnitudes and impact speeds.

Over the past several decades, many neck FE models have been developed. A human head-neck model was developed with the bony vertebrae modeled by shell elements, and the relevant muscles and ligaments were modeled by membranes and spring-damper elements, respectively [14]. Since solid muscles can affect the stabilization of the body due to compression stiffness and inertial effects, which significantly lessens the need for muscle activation in an impact, threedimensional solid muscle models with continuous material properties in which the friction among muscles is precisely realized have been adopted. Ejima et al. [5] simulated the passive solid cervical muscle tissues without considering anisotropy, that is, the nonviscoelastic properties of muscles. Frechede et al. $[6,15]$ considered the characteristic anisotropy of passive muscle tissues but defined the mechanical properties as linear elasticity. Hedenstierna [16], in Sweden, implemented muscle activation realized by a Hill element into passive solid neck muscles simulated by nonlinear elasticity and viscoelastic properties. Famous full-scale human FE models, such as the THUMS (total human model for safety) $[17,18]$ and the GHBMC (Global Human Body Models Consortium mid-sized male full-body model) [19, 20], included both active and passive muscle properties. However, the FE models developed during the early stages were not sufficiently accurate because of structural shortcomings and a lack of muscle activation $[5,6,14,15]$. A model developed by Hedenstierna [16] included no other parts of the human body, and the biofidelity of the transition between C7 and the thorax was not good enough. The THUMS and GHBMC models suffer from low computational efficiency and the geometric shortcomings of neck muscles [17-20]. Thus, to study the influence of neck muscle activation on neck injuries, a model overcoming the mentioned disadvantages is desired.

The aim of the present paper was at studying the influence of neck muscle activation on head and neck injuries of vehicle occupants in frontal impacts by using a mixed dummy-human FE model. When developing the model, the head-neck portion of the Hybrid III dummy model was replaced by a well-validated head-neck FE model with passive and active muscle characteristics. The mixed dummy-human FE model was validated by the NBDL (Naval Biodynamics Laboratory) in $15 \mathrm{G}$ frontal volunteer tests. The mechanism by which neck muscle activation affects the head and neck injuries of vehicle occupants in frontal impacts of three major intensities, low speed $(10 \mathrm{~km} / \mathrm{h})$, medium speed $(30 \mathrm{~km} / \mathrm{h})$, and high speed $(50 \mathrm{~km} / \mathrm{h})$, was studied.

\section{Methods and Materials}

A mixed dummy-human FE model was developed by replacing the head-neck portion of the Hybrid III model with a well-validated head-neck human model that can simulate the activation behavior of neck muscles. The mixed dummy-human FE model was then validated via frontal impact simulation in NBDL experiments [21, 22]. To study the mechanism by which muscle activation affects head and neck injury, the mixed dummy model was used to examine three major frontal impact intensities (i.e., $10 \mathrm{~km} / \mathrm{h}, 30 \mathrm{~km} / \mathrm{h}$, and $50 \mathrm{~km} / \mathrm{h}$ ). 


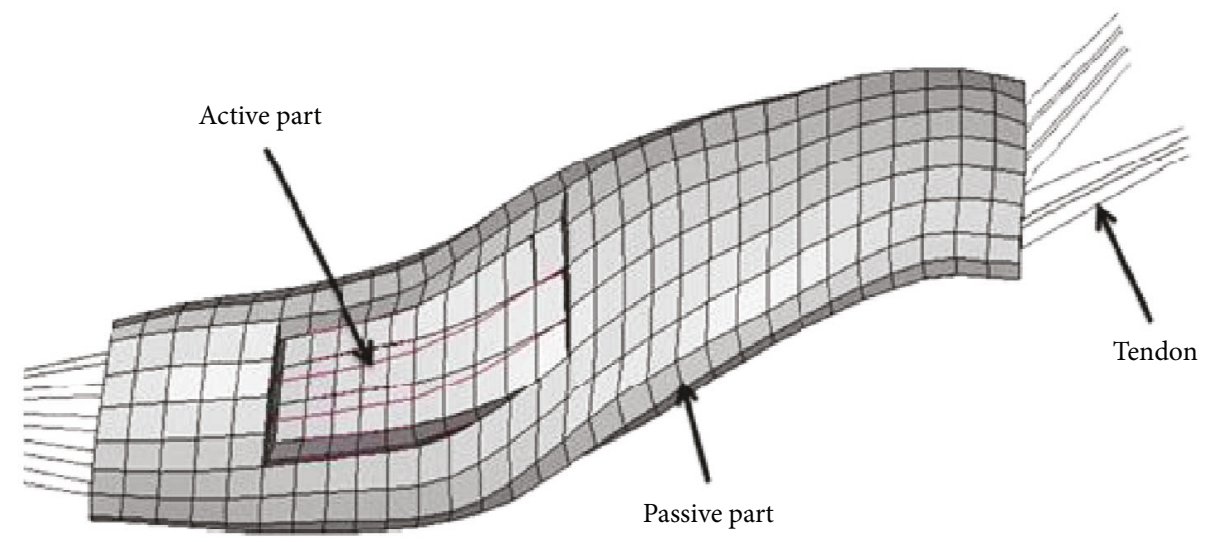

Figure 3: A coupled single muscle.

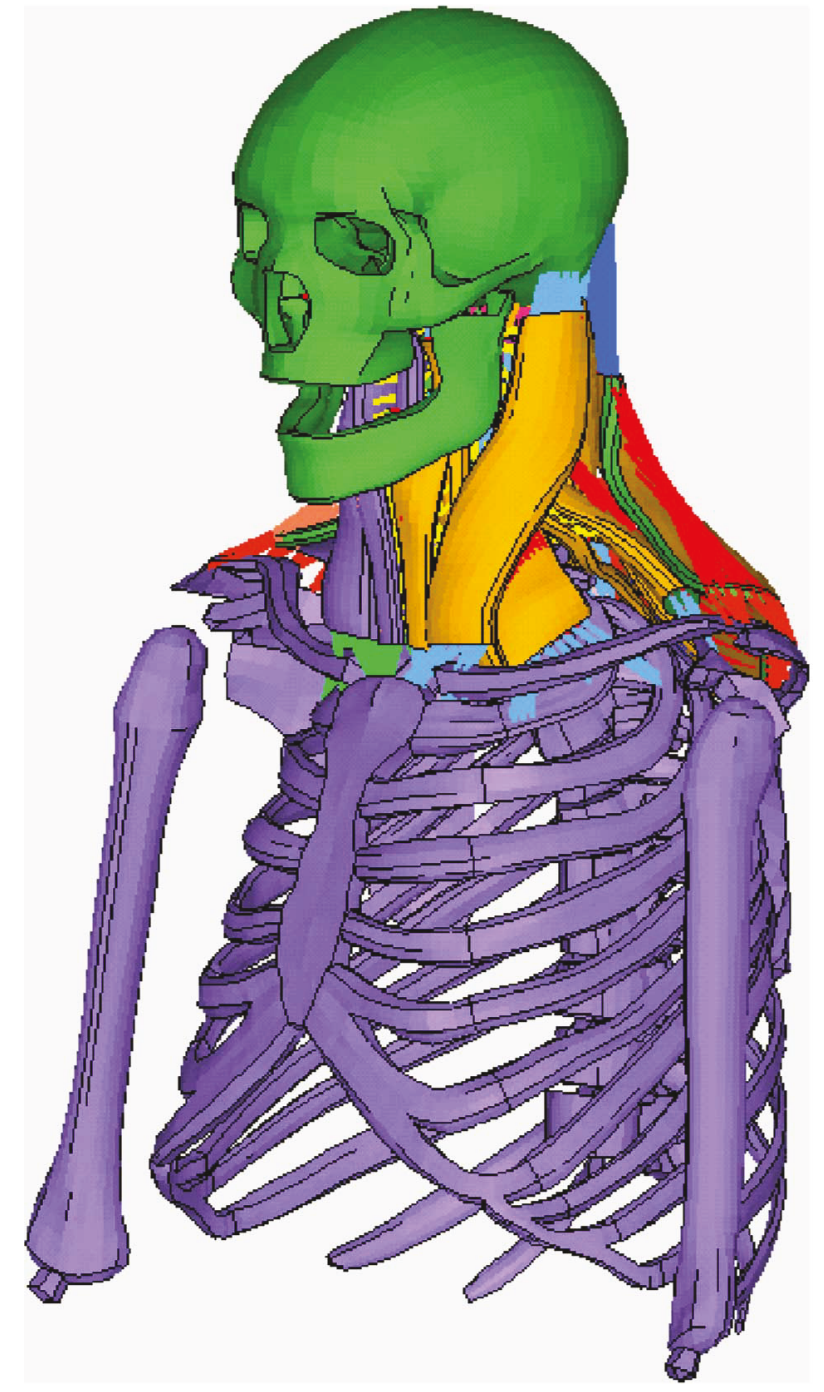

Figure 4: Head-neck human FE model.

\subsection{Development of the Mixed Dummy-Human FE Model}

2.1.1. Head-Neck Human FE model. The head-neck human FE model represents a 50th percentile male, and it was developed from the basic head-neck model (Figure 1) validated by Yang and Yao [23]. This basic model has a detailed anatomical structure, including a skull, cervical vertebra (C1-C7), intervertebral discs, facet joints, cervical ligaments, and muscles that were modeled by $1 \mathrm{D}$ beam elements. The skull and shoulder were defined to be rigid because this model is mainly used for neck injury-related studies. The detailed solid neck muscle model (Figure 2) was developed based on neck MRI images of a 50th percentile adult male [24] and integrated into the basic head-neck human FE model using a kriging method by mapping the origins and terminations as well as coordinate information of the neck muscles of volunteers to the basic head-neck model (the original model includes detailed thorax geometry) $[25,26]$. Kriging is a type of optimal interpolation first proposed by DG Krige, a geologist in South Africa. For detailed information about the kriging method, please refer to the literature [27].

A single-muscle FE model consisted of three parts: the tendon modeled by a beam element, the passive muscle belly modeled by a solid element, and the active muscle modeled by a beam element (Figure 3). The active part of the model was merged into the passive part with shared nodes. The active part was modeled by a Hill-type element defined as MAT_156 material in the LS-DYNA software, and the passive part was defined as a hyperelastic model in Ogden material (MAT 77 in LS-DYNA). A detailed material definition can be found in a study conducted by $\mathrm{Li}$ et al. [25]. Figure 4 shows the head-neck human FE model developed from models illustrated above.

2.1.2. Hybrid III Dummy FE Model. The Hybrid III mechanical dummy was developed by General Motors in 1976 and was widely used by vehicle companies. The relative FE model applied in the present study was a commercial model developed using the LS-DYNA software. The model includes a head, neck, chest, abdomen, pelvis, and limbs, consisting of 7784 nodes and 4412 elements (Figure 5).

2.2. Mixed Dummy-Human FE Model. In terms of the computational efficiency, a full-scale human FE model such as 


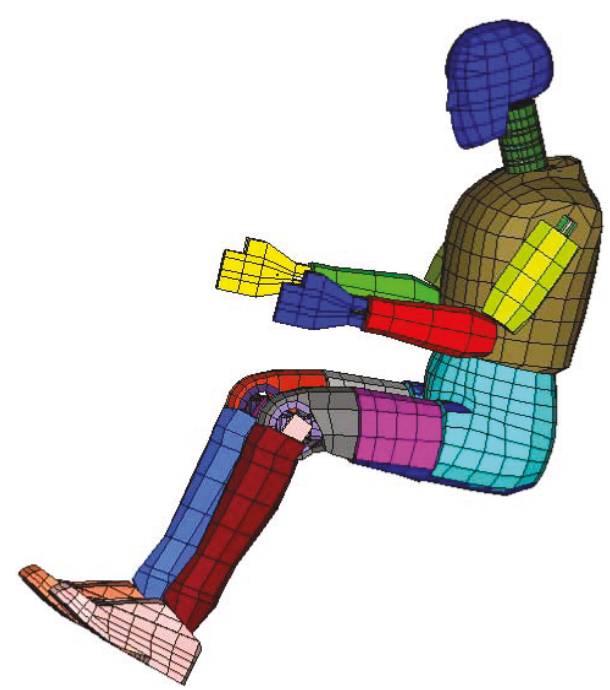

Figure 5: Hybrid III dummy.

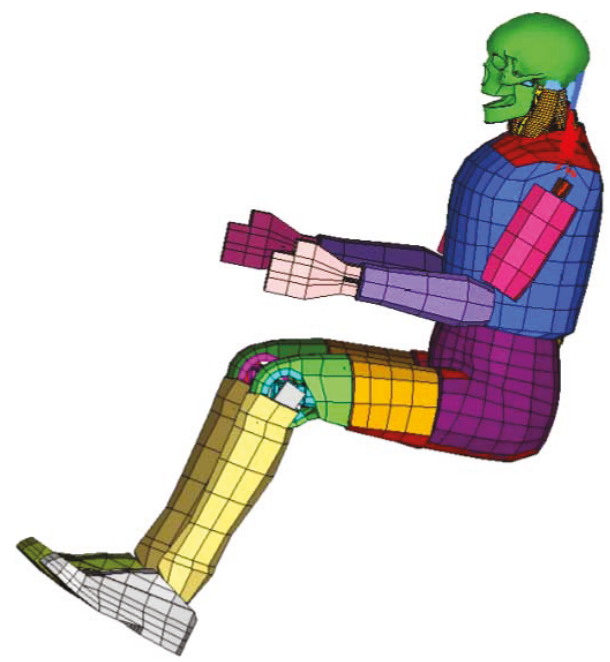

Figure 6: The mixed dummy-human FE model.

GHBMC or THUMS, with detailed soft tissues, such as muscles, brains, and the haslet, is time consuming. Although the mechanical dummy FE model has good computational efficiency, it has less biofidelity than does the full-scale human FE model. In this study, we decided to combine the advantages of both models by developing a mixed dummyhuman FE model, replacing the head-neck portions of Hybrid III with the head-neck of a human FE model, as previously mentioned. This mixed model has good computational efficiency and good biofidelity for studying the effects of muscle activation on head and neck injuries and other related biomechanical studies. The kriging method was also used to develop the complex model. The outlines and coordinate information of the $\mathrm{T} 1$ of the head-neck human $\mathrm{FE}$ model were mapped to the $\mathrm{T} 1$ of the dummy parts and connected with anatomical joints $[27,28]$. The rigid thorax and T1 of the head-neck human FE model and the dummy FE model were used to form a corresponding coordinate system for adjusting the posture of the mixed FE model. The mixed

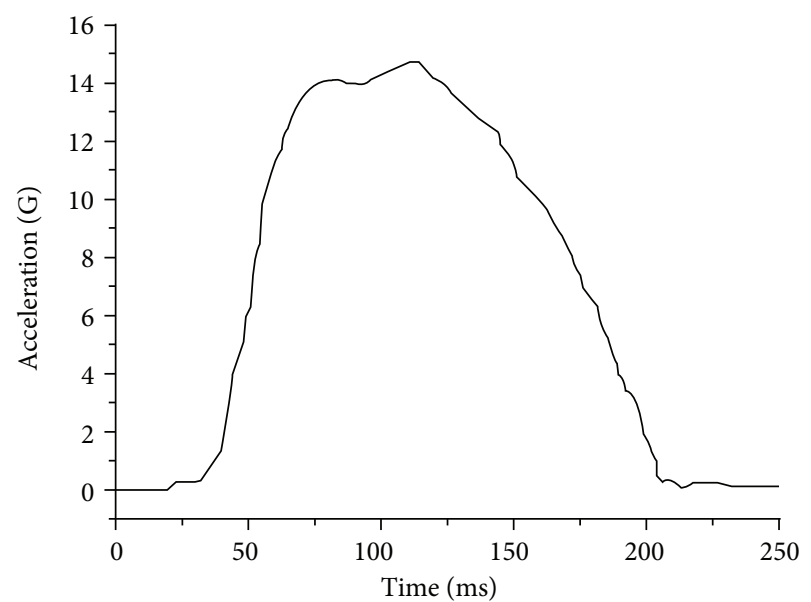

FIgURE 7: Loading acceleration in NBDL tests.

dummy-human model has a precrash sitting posture similar to that of the Hybrid III FE dummy, as shown in Figure 6.

\subsection{Validation of the Mixed Dummy-Human FE Model}

2.3.1. NBDL Experiment. The mixed dummy-human FE model was validated based on $15 \mathrm{G}$ NBDL frontal volunteer tests. Volunteers (young, well-trained marines) were seated in an upright position on a rigid seat mounted on a HYGE accelerator and exposed to a short-duration acceleration that simulated a frontal collision. Accelerometers and photographic targets were mounted on the subject and used to monitor the resultant three-dimensional motions of the head and T1. A detailed description of the instrumentation and the test methods were provided by Ewing et al. [21,22]. The peak value of the sled acceleration (i.e., the mean value of the sled acceleration-time history) was $15 \mathrm{G}$, and the speed change was greater than $17 \mathrm{~m} / \mathrm{s}$ (Figure 7). The dynamic responses of the head and neck of the volunteers were recorded. The experimental corridors used in the validation process, obtained from the NBDL experiments [22], were expressed as the average volunteer response plus or minus the standard deviation [29].

2.3.2. Simulation Setting. Since the seating posture has a great influence on the head injury of an occupant [30], to minimize its impact, the mixed dummy-human FE model was set in a normal automotive posture (Figure 8 ) in a gravity field, as in the NBDL experiment. The dummy was seated on a rigid seat that was connected to a rigid plate representing the vehicle. The lower arm was placed on the thigh. The configuration about the occupant restraint system was mainly adopted from the commercial FE vehicle model [31] used in this study. The seat belt included a retractor, slip rings, pretensioner, a ribbon modeled by $1 \mathrm{D}$ beam elements and $2 \mathrm{D}$ shell elements, and anchor nodes connected to rigid seats. The $1 \mathrm{D}$ beam elements were able to simulate the sliding effect of the slip rings. The force versus engineering strain curves for the seat belt loading and unloading, the force versus time curve for the retractor, and the preload curve for the pretensioner are described in Figure 9. 


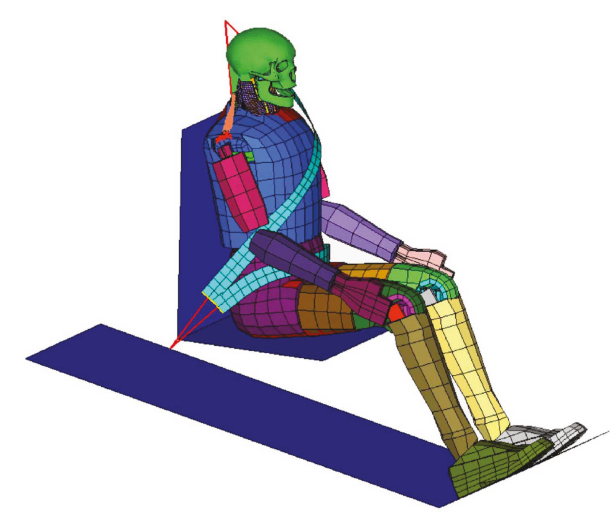

(a)

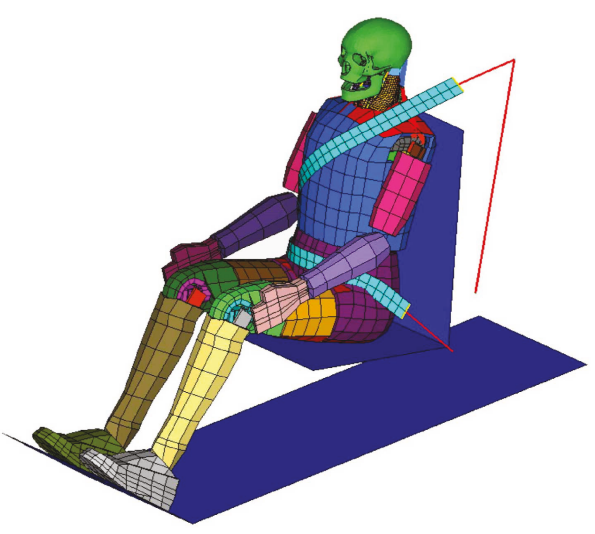

(b)

FIgURE 8: The mixed dummy-human FE model in an automotive posture.

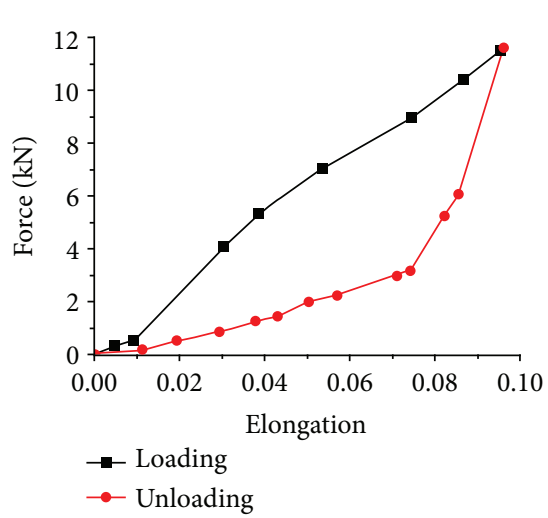

(a) Force versus strain curves for the seat belt

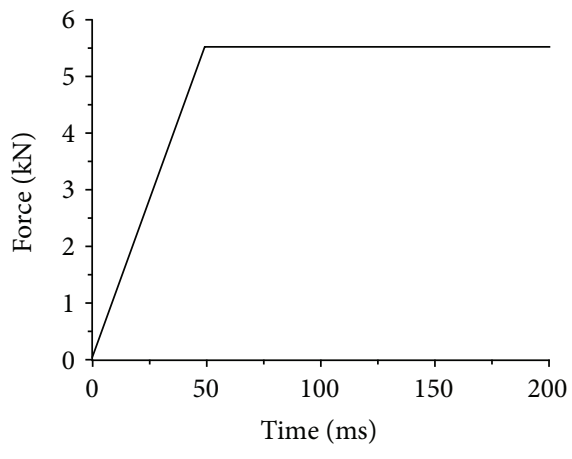

(b) Force versus time curve for the retractor

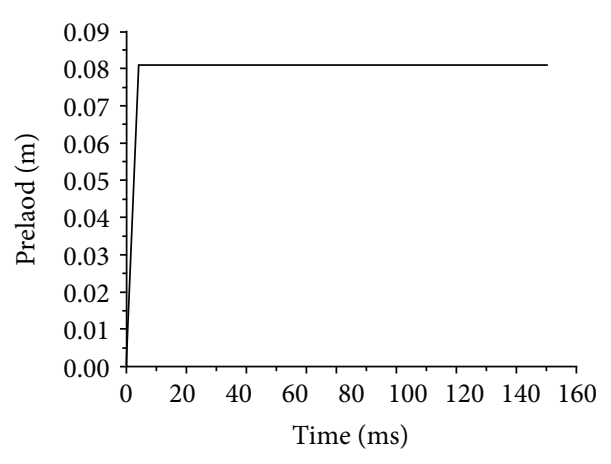

(c) Preload curve for the pretensioner

FIgURE 9: Loading curves applied to the seat belt system.

The active contracting forces that model muscle activation were activated by $A(t)$. However, the time history of muscle activation was not immediately activated at the time of the collision. Instead it was

$$
t_{\text {act }}=t_{\text {trigger }}+t_{\text {reflex }}
$$

where $t_{\text {trigger }}$ is defined as a certain sensory threshold time and $t_{\text {reflex }}$ is a neural reflex time that describes the excitation and activation dynamics, respectively. The two constants throughout the study were set at $30 \mathrm{~ms}$ and $40 \mathrm{~ms}$ for $t_{\text {trigger }}$ and $t_{\text {reflex }}$, respectively, by methods referring to a study conducted by van der Horst [29].

The $A(t)$ time history, including parameters such as the maximum activation level $\left(\right.$ Act $\left._{\max }=1\right)$, the time the first maximum activation level is reached $\left(t_{\text {peak }}=95 \mathrm{~ms}\right)$, and the time the end of activation is reached $\left(t_{\text {end }}=250 \mathrm{~ms}\right)$, are shown in Figure 10.

To make the dynamic responses of the head and neck clearly understood, the methods used to set the responses in the simulation are shown in Table 1.

The impact acceleration curve (Figure 7) generated from the hydraulic impactor was used as the input for the simulation, and the run time of the simulation was set to $200 \mathrm{~ms}$

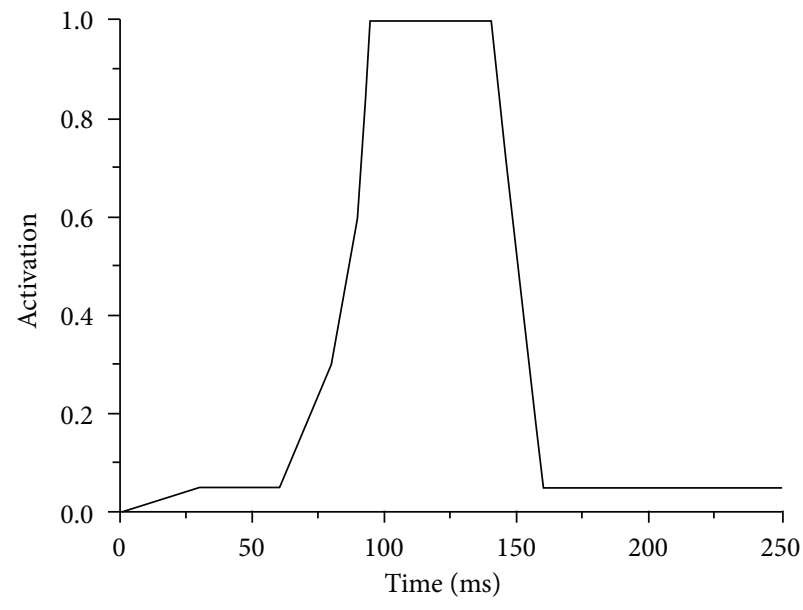

Figure 10: Muscle activation.

because the dynamic indicators in the NBDL experiment recovered to a low level in approximately $200 \mathrm{~ms}$. The time histories of the head rotational angle, neck rotational angle, head angular acceleration, and head resultant acceleration were compared with the experimental curves and the simulation results of head-neck model by Cao et al. [26]. 
TABLE 1: Response settings.

\begin{tabular}{lc}
\hline Response parameters & With respect to \\
Head resultant acceleration $^{\mathrm{a}}$ & Global system \\
Head angular acceleration $^{\mathrm{b}}$ & System in T1 \\
Head rotational angle $^{\mathrm{c}}$ & System in T1 \\
Neck rotational angle $^{\mathrm{d}}$ & System in T1 \\
\hline
\end{tabular}

${ }^{a}$ Resultant acceleration of the center of gravity of the head (CG). ${ }^{b}$ Angular acceleration along a straight line connecting the occipital condyles (OC) to CG in the sagittal plane. ${ }^{c}$ Angle of a straight line connecting OC to CG in the sagittal plane. ${ }^{\mathrm{d}}$ Angle of a straight line connecting OC to $\mathrm{T} 1$ in the sagittal plane.

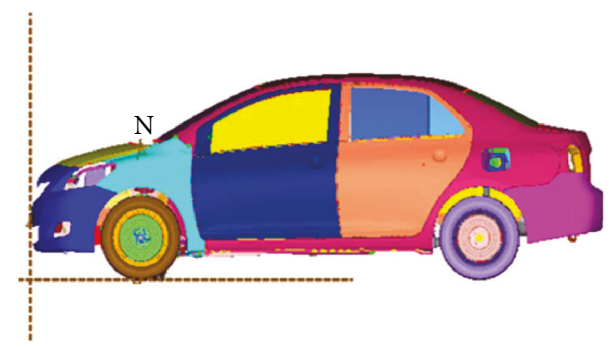

FIgURE 11: The validated vehicle model.

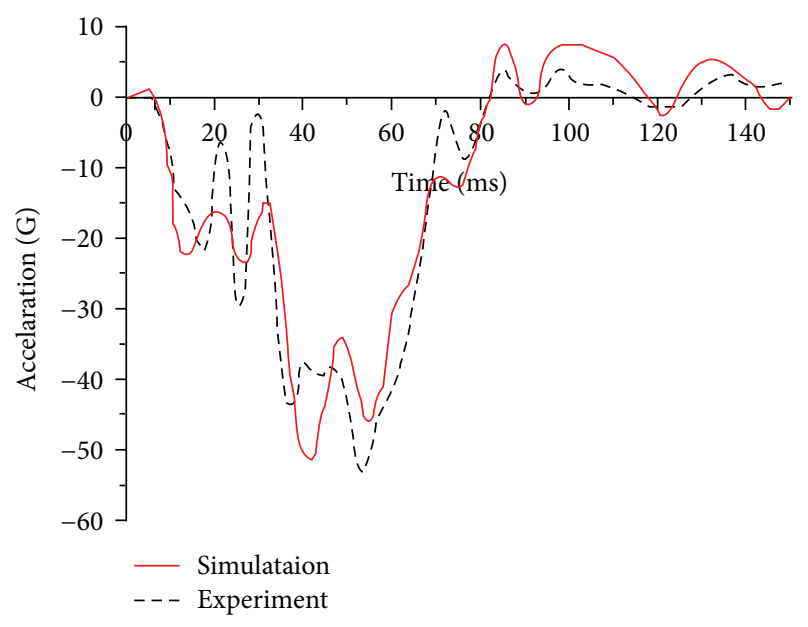

FIgURE 12: Vehicle acceleration curves.

2.4. Influence of Neck Muscle Activation of Head and Neck Injuries under Various Intensities. The influence of neck muscle activation on head and neck injuries in a frontal crash was considered for three impact intensities: $10 \mathrm{~km} / \mathrm{h}, 30 \mathrm{~km} /$ $\mathrm{h}$, and $50 \mathrm{~km} / \mathrm{h}$, representing low-speed, medium-speed, and high-speed impact velocities in a 100\% full vehicle frontal impact simulation, respectively. The effectiveness of the vehicle (Figure 11) was successfully validated by comparing the acceleration of the rear seat in a $100 \%$ full vehicle frontal impact simulation at $50 \mathrm{~km} / \mathrm{h}$ to that in the experiment (Figure 12) [31]. The impact pulses of the B-pillar (Figure 13), retrieved from the simulations of a $100 \%$ full vehicle frontal impact at the three intensities mentioned above, were used as the input for the simulations.

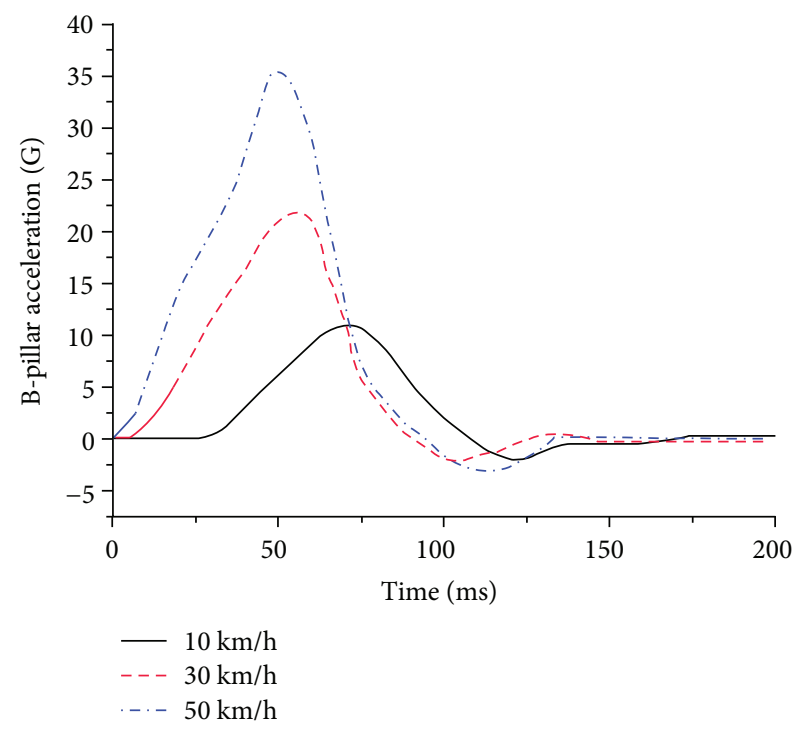

FIGURE 13: Loading acceleration curves for a frontal impact simulation.

The muscle activation was the same as that utilized to validate the mixed dummy human FE model, and the run time for the simulations was set to $200 \mathrm{~ms}$.

\section{Results}

3.1. Model Validation. The overall dynamic responses of the present model are shown in Figure 14. From $0 \mathrm{~ms}$ to $50 \mathrm{~ms}$, the model was in a static equilibrium state because the impact pulse in this period was set to 0 for presimulation, with gravity alone acting on the mixed model (Figure 14(a)). After this period, as the impact pulse increased, the torso of the dummy moved forward and separated from the seat back (Figure 14(b)), while the head moved hysterically with a slight neck extension because the neck muscles were not ready to move. However, the muscle began to activate and the head moved together with the thorax and neck. Beginning at $105 \mathrm{~ms}$, according to the behavior of the restraint system, the torso movement was limited while the head began to wrap forward, with the neck flexion assuming an $S$ shape (Figure 14(c)). In this period, the neck muscles were fully activated but still could not provide adequate torque to maintain the stability of the head. The head then reached an extreme position at $165 \mathrm{~ms}$ (C shape in Figure 14(d)) and began to wrap backward as the neck extended. Between $181 \mathrm{~ms}$ and $200 \mathrm{~ms}$, the head and neck gradually rebounded due to muscle traction.

The dynamic responses of the head and neck were consistent with the NBDL experimental curves. The time points (approximately $98 \mathrm{~ms}$ and $150 \mathrm{~ms}$ ) for the peak value of the resultant acceleration of the head in the volunteer response were accurate enough, but the acceleration value was only slightly above the curve during the initial period due to the precrash equilibrium (Figure 15(a)). The value of the first peak fell exactly in the channel and the second exceeded it by approximately $6 \%$. Other outputs showed a similar tendency. The head angular acceleration was in good agreement 


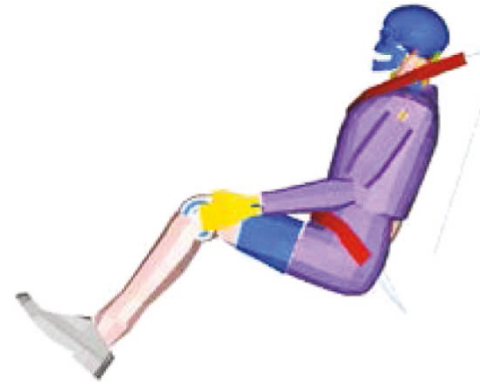

(a) $50 \mathrm{~ms}$

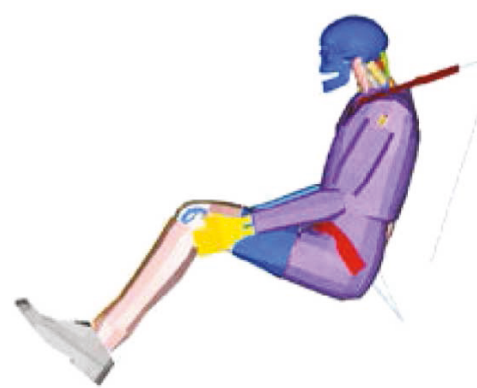

(c) $110 \mathrm{~ms}$

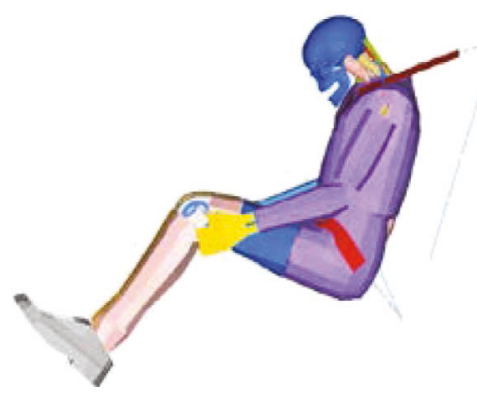

(e) $170 \mathrm{~ms}$

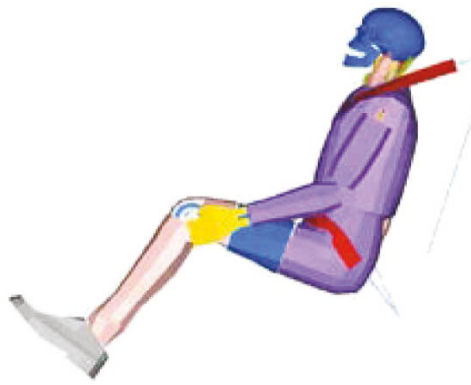

(b) $80 \mathrm{~ms}$

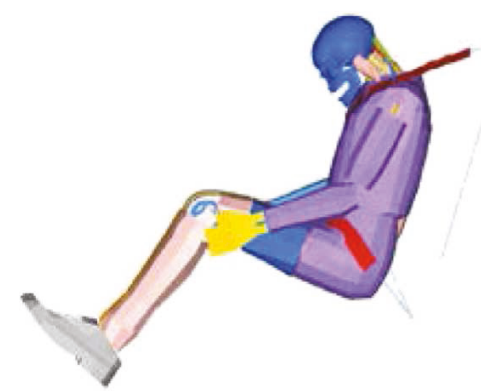

(d) $140 \mathrm{~ms}$

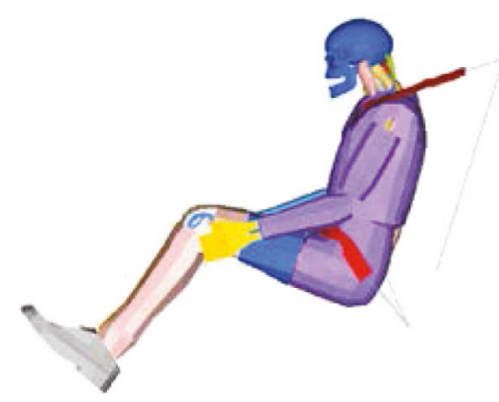

(f) $200 \mathrm{~ms}$

Figure 14: Dynamic responses in a frontal impact simulation.

with the curves apart from a small amount of overload at the end (Figure 15(b)). Compared to the output from the study conducted by Cao et al. [26], the amount outside the curve at the final stage was much smaller. From 50 to $100 \mathrm{~ms}$, the head rotational angle (Figure 15(c)) was below the range of the channel and the time that the maximum value was reached was almost the same as that in the experimental results, while the head rotational angle in the study of Cao et al. fell exactly within the channel, and its peak value was $18.9 \%$ lower than that of the present study. The neck rotational angle (Figure 15(d)) was outside the curve between $50 \mathrm{~ms}$ and $100 \mathrm{~ms}$ but fell within the channel before reaching the peak value. Although the maximum value stayed almost the same as for the volunteer response, the time the maximum was reached was $10 \mathrm{~ms}$ early. In contrast to the neck rotational angle in the study of Cao et al., the trend of the neck rotational angle in the present study was more consistent with that of the NBDL experimental curves.

3.2. Muscle Activation Behavior. A comparison of the head dynamic responses with the muscles activated or not activated (denoted the active or passive model, resp.) is shown in Figures $16-18$. In a low-speed $(10 \mathrm{~km} / \mathrm{h})$ frontal impact simulation, two peak values of the resultant acceleration were observed in both the active and passive models. The resultant acceleration reached its first peak of $18.9 \mathrm{G}$ at $105 \mathrm{~ms}$ in the active model and at $24 \mathrm{G}$ at $97 \mathrm{~ms}$ in the passive model. The second peak time in the passive model was $6 \mathrm{~ms}$ later than that in the active model, and the acceleration value differed by $2.5 \mathrm{G}$. The maximum angular acceleration reached $1496 \mathrm{rad} / \mathrm{s}^{2}$ at $98 \mathrm{~ms}$ in the active model, and it was $1478 \mathrm{rad} / \mathrm{s}^{2}$ at $103 \mathrm{~ms}$ in the passive model.

For the medium-speed $(30 \mathrm{~km} / \mathrm{h})$ frontal impact simulation results, the peak head resultant accelerations in the active and positive models occurred at $89 \mathrm{~ms}$ and $97 \mathrm{~ms}$, respectively; the first peak of the former was reduced by approximately $18 \%$, and the second peak value was reduced by more than $27 \%$. Meanwhile, the peak angular acceleration in both models was observed at the same time. However, the peak angular acceleration in the passive model was approximately $20.8 \%$ higher than that in the active model.

In a high-intensity impact $(50 \mathrm{~km} / \mathrm{h})$, a dual peak was also found between $90 \mathrm{~ms}$ and $102 \mathrm{~ms}$ in both models for the outputs of head resultant accelerations, but the peak 

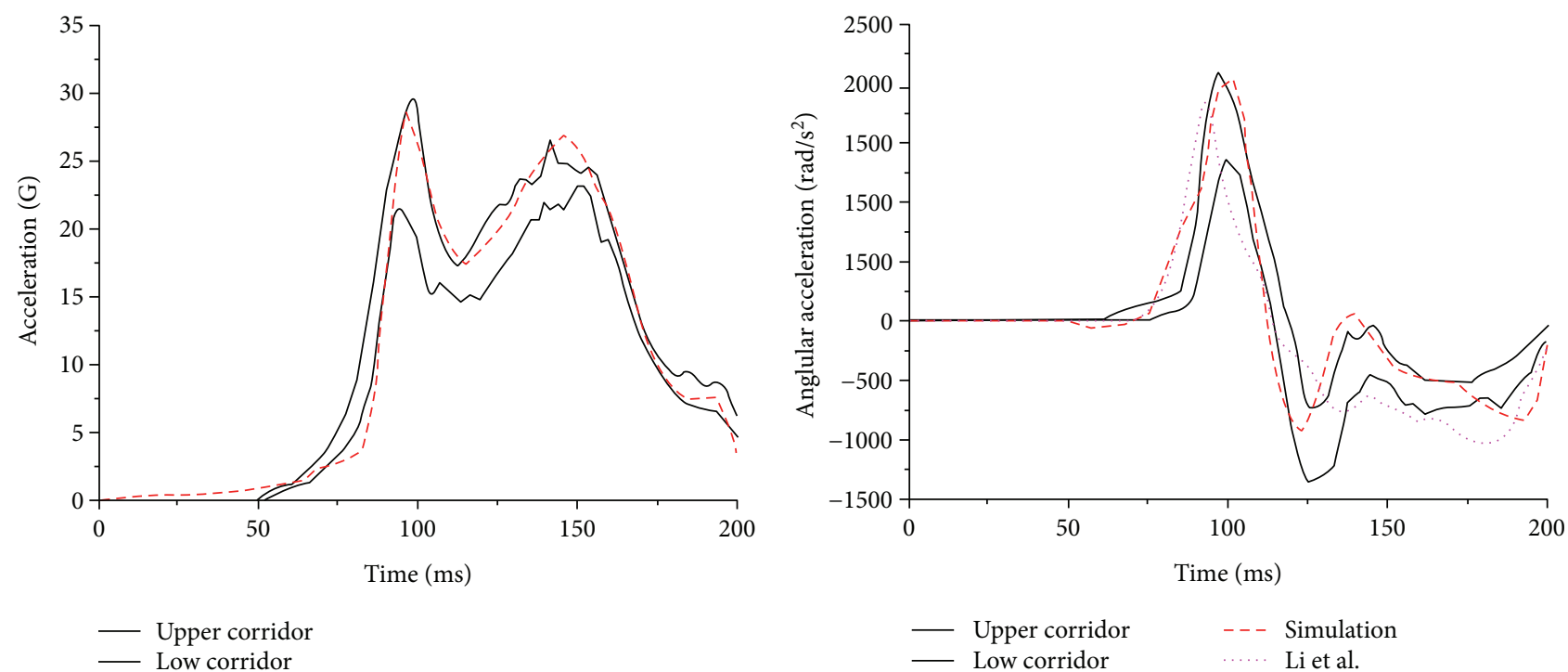

\section{- Upper corridor \\ - Low corridor \\ - - Simulation}

(a) Head resultant acceleration

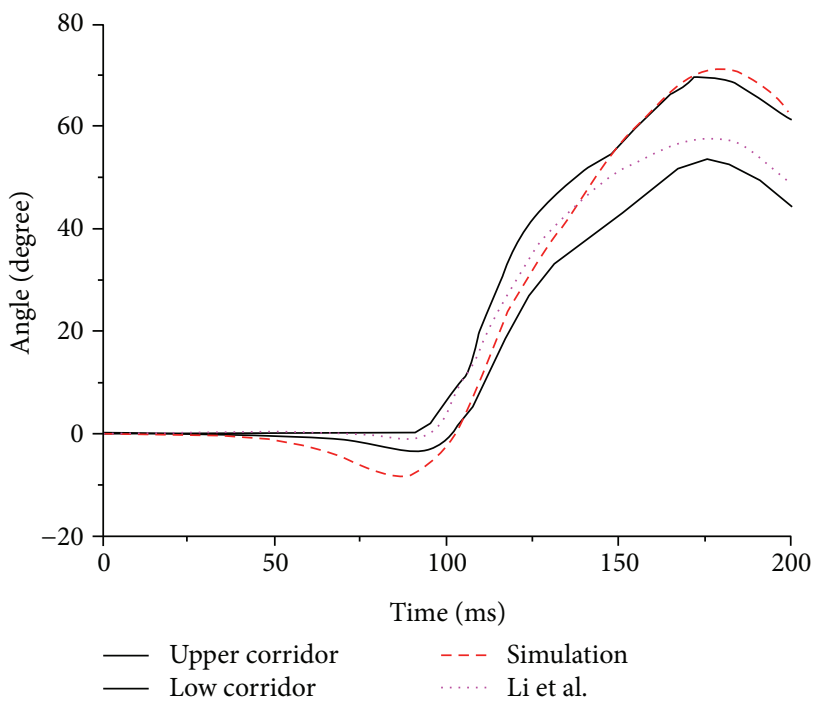

(c) Head rotational angle (b) Head angular acceleration

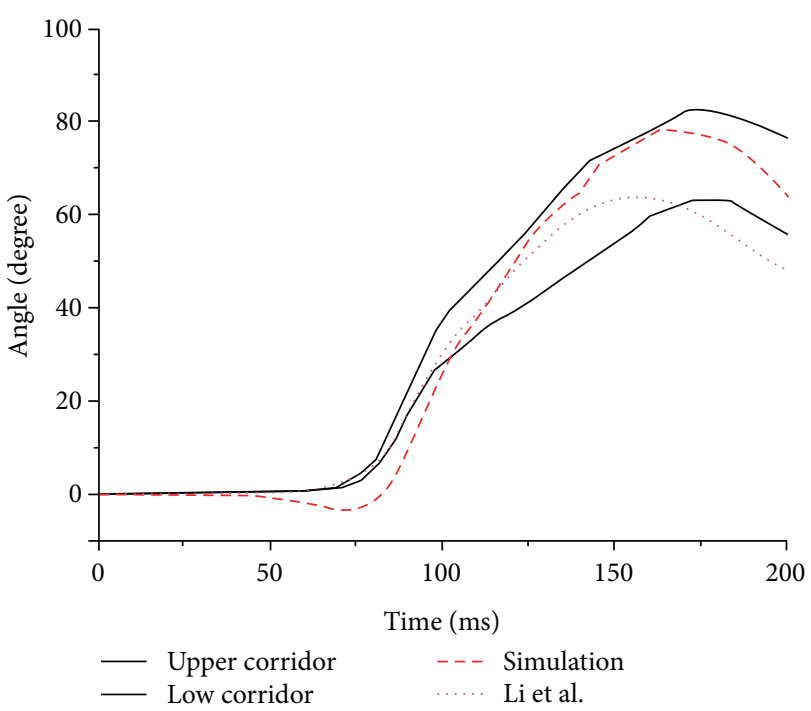

(d) Neck rotational angle

FIGURE 15: Dynamic response curves of the head and neck in a frontal impact simulation.

in the passive model was approximately $24 \%$ higher than that in the active model. During the extension period, the peak in the passive model was $97.8 \mathrm{G}$, while it was $57 \mathrm{G}$ in the active model, which was much lower. The peak angular acceleration in both models occurred at approximately $92 \mathrm{~ms}$, while the peak in the passive model was $15.3 \%$ higher than that in the active model.

The stresses on the intervertebral discs are shown in Figures 19-21. Overall, as the impact intensity increased, the stress on the intervertebral discs increased. The stress in the active model was much lower compared to that in the passive model especially for the $\mathrm{C} 2-\mathrm{C} 3, \mathrm{C} 3-\mathrm{C} 4$, and C4-C5 discs in a low-speed impact intensity crash. For the $\mathrm{C} 2-\mathrm{C} 3$ disc of the model in a low-speed impact, the maximum pressure was $0.103 \mathrm{GPa}$ in the passive model, more than 17 times the $0.005684 \mathrm{GPa}$ observed in the active model. The maximum shear stress in the passive model was $0.0252 \mathrm{GPa}$, exceeding by $129 \%$ the $0.011 \mathrm{GPa}$ in the active model. Additionally, the maximum von Mises stress of the C4-C5 disc in the passive model was approximately 1.58 times higher than that in the active model. However, the maximum shear stress on the $\mathrm{C} 2-\mathrm{C} 3$ and C4-C5 discs, the maximum pressure in the $\mathrm{C} 2-\mathrm{C} 3$ and C5-C6 discs, and the maximum von Mises stress in the C2-C3 and C3-C4 discs in high-speed impact showed the opposite tendency. For the $\mathrm{C} 2-\mathrm{C} 3$ disc, the maximum von Mises stress in the active model was approximately $33 \%$ higher than that in the passive model. The maximum shear stress and the maximum pressure in the active model in a medium-speed impact were lower than those in the passive model, while the maximum von Mises stress showed the opposite tendency. 


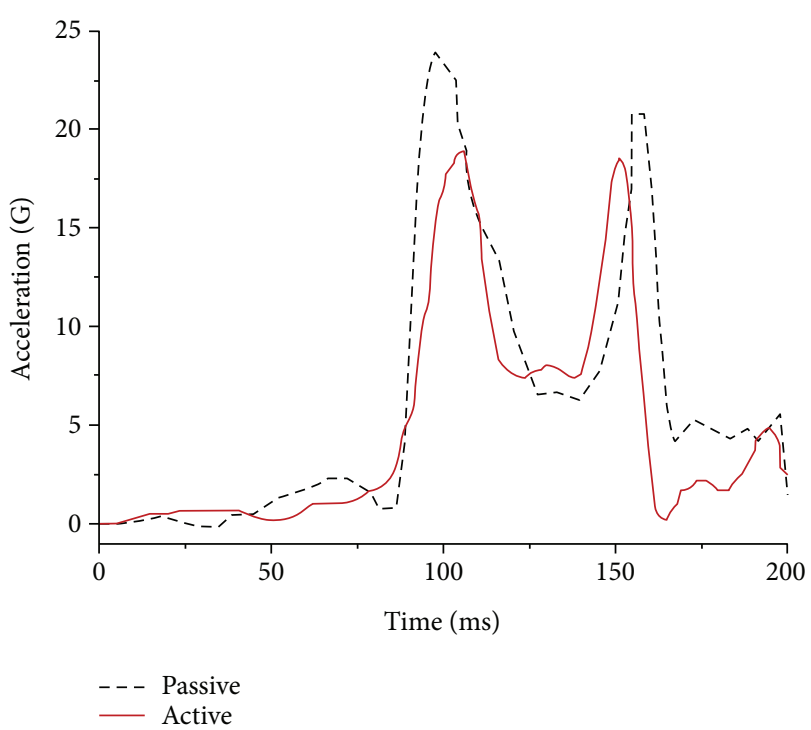

(a) Head resultant acceleration

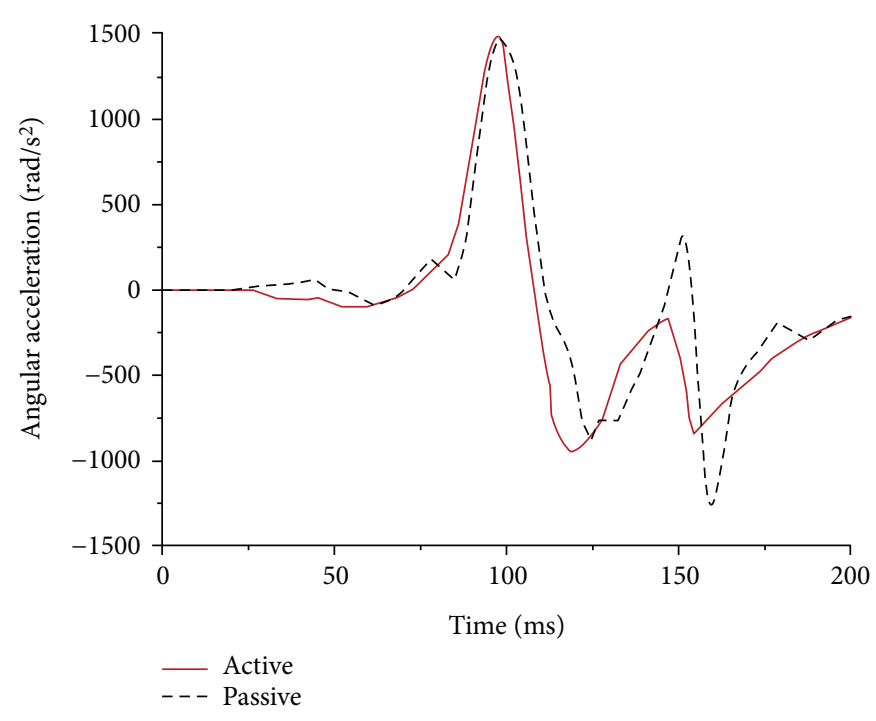

(b) Head angular acceleration

FIgURE 16: Dynamic response curves of the head and neck in a frontal impact simulation under $10 \mathrm{~km} / \mathrm{h}$.

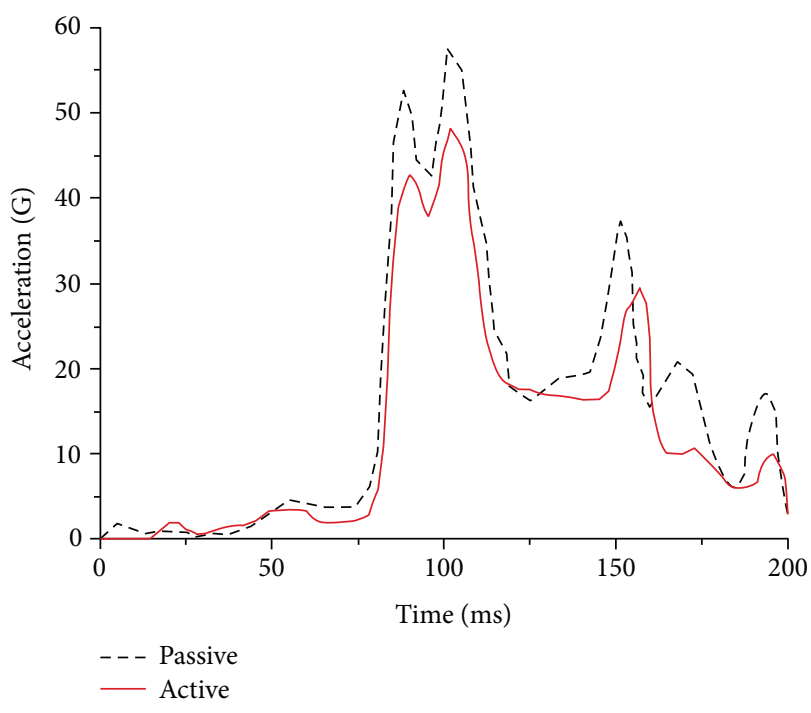

(a) Head resultant acceleration

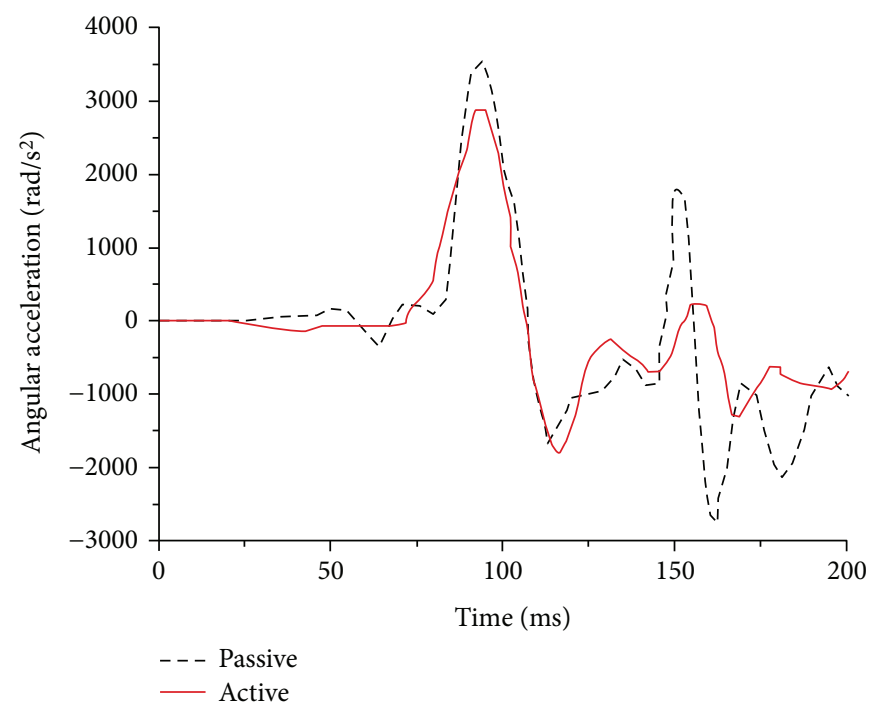

(b) Head angular acceleration

FIgURe 17: Dynamic response curves of the head and neck in a frontal impact simulation under $30 \mathrm{~km} / \mathrm{h}$.

\section{Discussion}

In the present paper, a mixed dummy-human FE model was developed. This model was validated according to NBDL volunteer frontal impact experiments. The influence of neck muscle activation on head-neck injuries of occupants in frontal impacts was analyzed using the mixed dummy-human FE model in three impact intensities, that is, $10 \mathrm{~km} / \mathrm{h}, 30 \mathrm{~km} / \mathrm{h}$, and $50 \mathrm{~km} / \mathrm{h}$. The dynamic responses of head and biomechanical responses of cervical intervertebral discs, including maximum von Mises stress, maximum shear stress, and maximum pressure, were compared in terms of whether the neck muscle was activated.
The mixed dummy-human FE model turned out to have good biofidelity for the simulation compared to the NBDL experimental corridors. The mixed model showed good computational efficiency for a $200 \mathrm{~ms}$ frontal impact simulation, requiring approximately 5 hours using a computer CPU with a 40 -core Intel(R) E5-2670 v2 at $2.50 \mathrm{GHz}$ processor. Because of the dummy torso behavior, the head-neck dynamic responses were more reliable, as the previous human head-neck single model could only be loaded on C7 and the driving behavior between vertebras or between torso and neck could thus not be simulated. In the study conducted by Li et al. [26, 28, 32], using only the previous human head-neck model, two peaks for the head resultant 


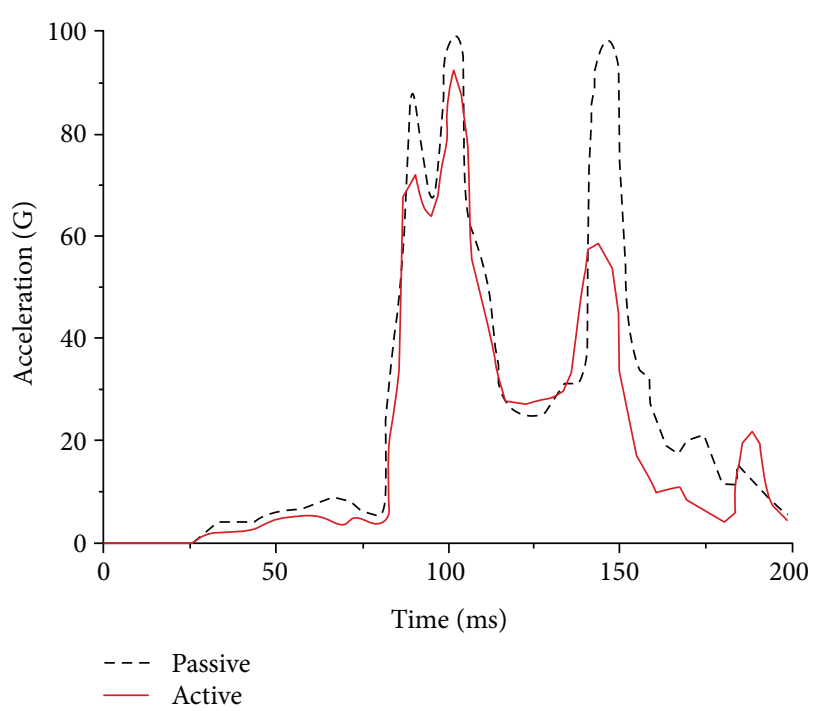

(a) Head resultant acceleration

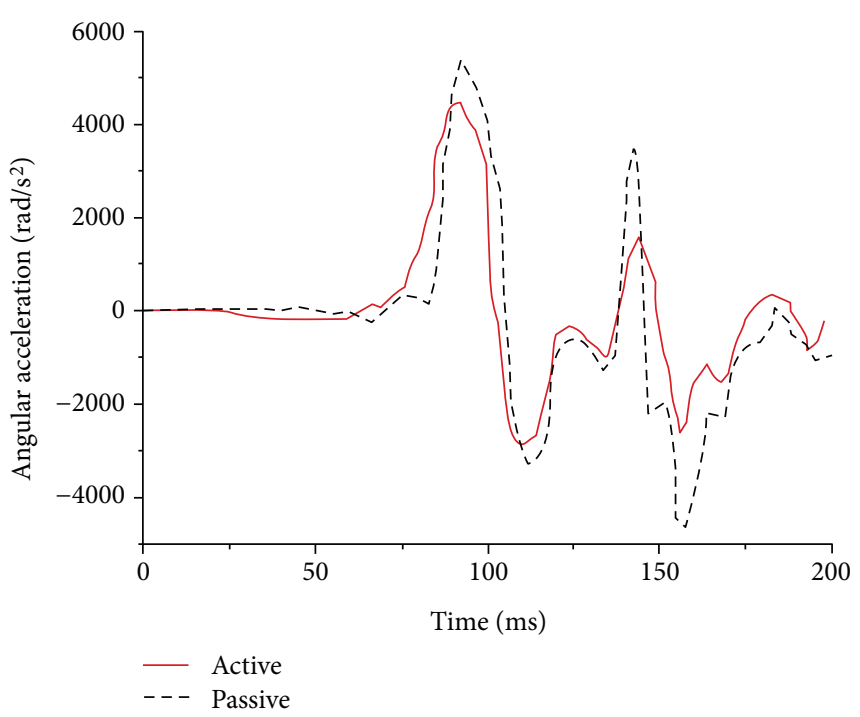

(b) Head angular acceleration

FIGURE 18: Dynamic response curves of the head and neck in a frontal impact simulation under $50 \mathrm{~km} / \mathrm{h}$.

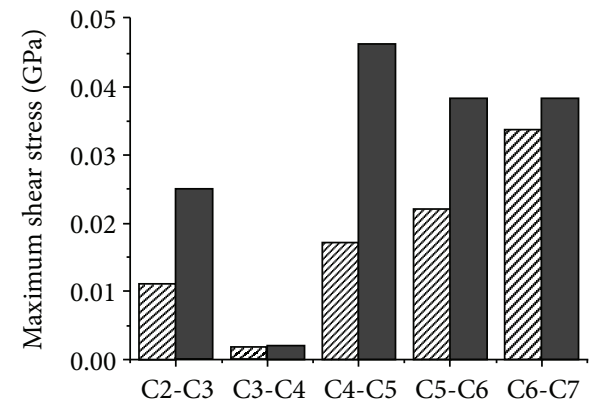

Active
$\square$ Passive

(a) Low impact

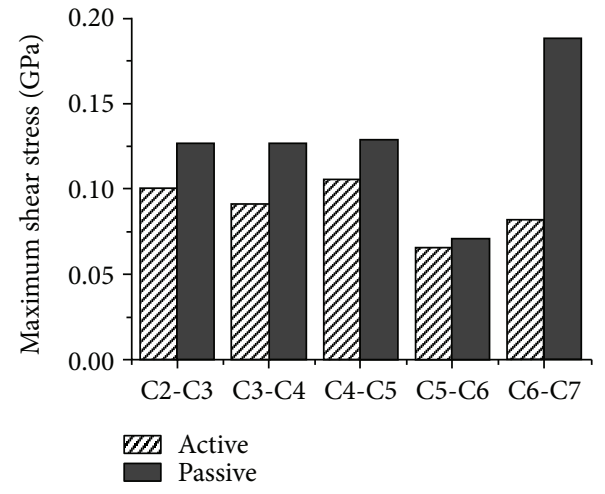

(b) Medium impact

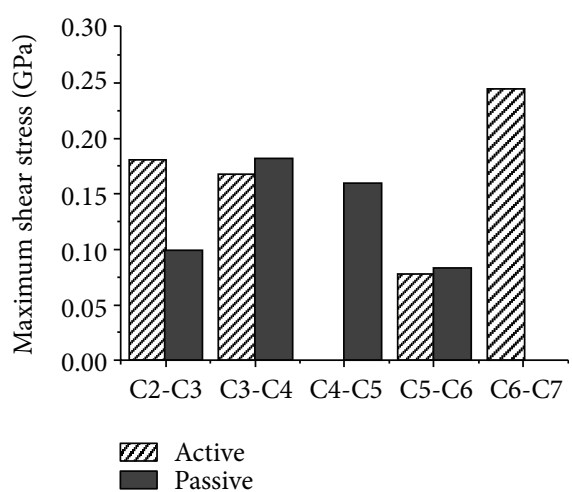

(c) High impact

FIgURE 19: Maximum shear stress of intervertebral discs at various impact intensities.

acceleration were observed instead of one (as in the present study), and this phenomenon was also seen in similar studies [8] when the simulation used a head-neck model without torso parts.

In terms of the head dynamic responses for the different frontal impact intensities, including the linear acceleration and angular acceleration that were greatly relevant to the head HIC [33-35] and head AIS injury level [36], respectively, activation of neck muscles during a frontal impact seems to be an important factor in reducing the head injury risk. The peak head resultant acceleration in the passive model was $27 \%$ (low intensity) to $24 \%$ (high intensity) 


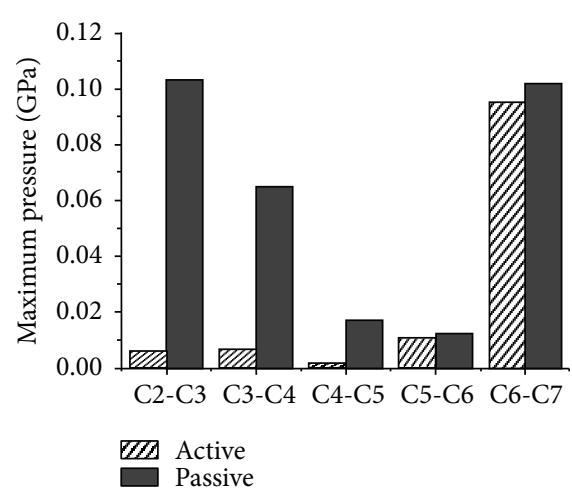

(a) Low impact

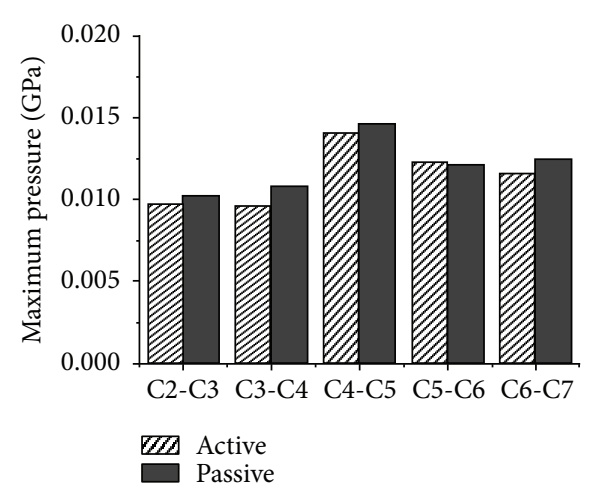

(b) Medium impact

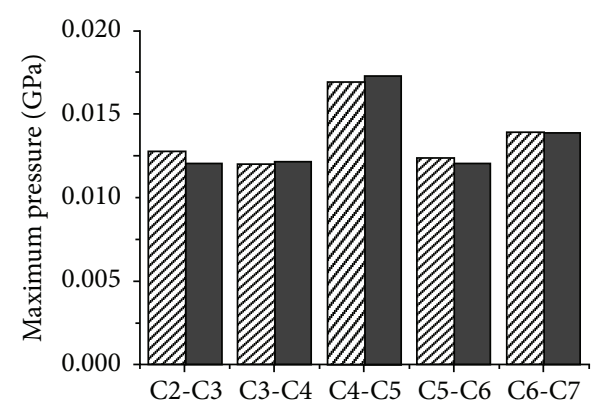

Z7/7 Active

(c) High impact

FIGURE 20: Maximum pressure of intervertebral discs at various impact intensities.

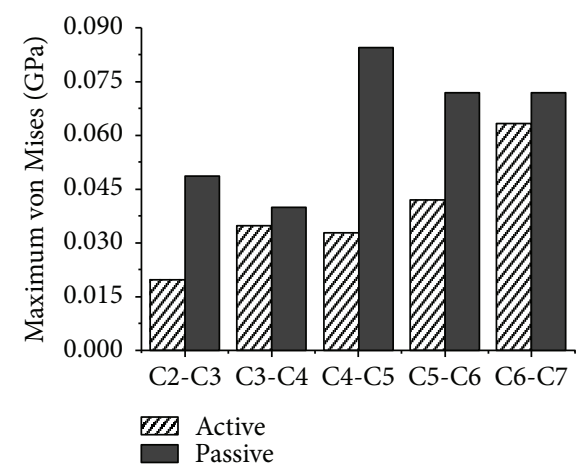

(a) Low impact

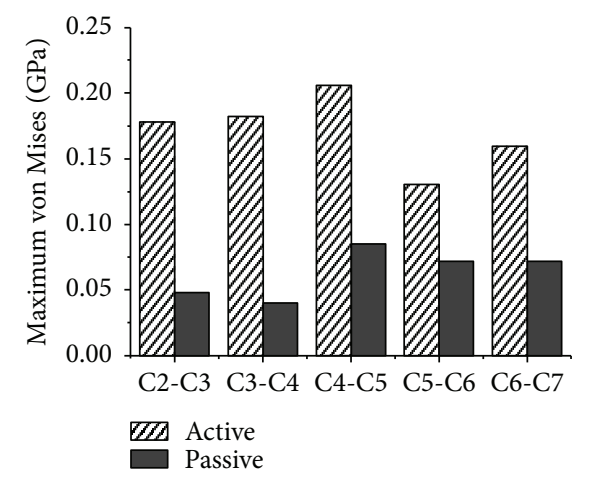

(b) Medium impact

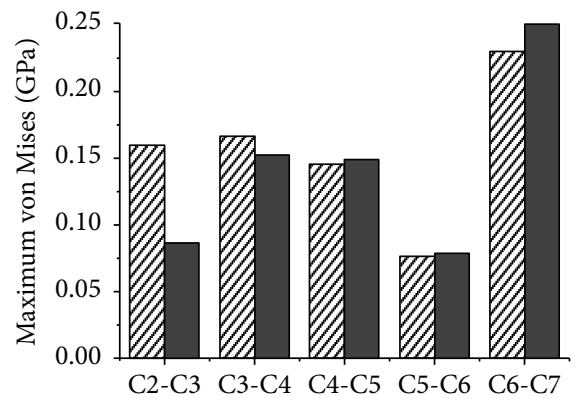

IIIJ Active

(c) High impact

FIGURE 21: Maximum von Mises stress of intervertebral discs at various impact intensities. 
TABLE 2: Relationship between AIS level and injury tolerance of head angular acceleration [36].

\begin{tabular}{lc}
\hline AIS level & Injury tolerance \\
AIS1 & $\ddot{a}<1700 \mathrm{rad} / \mathrm{s}^{2}$ \\
AIS2 & $1700 \mathrm{rad} / \mathrm{s}^{2}<\ddot{a}<3000 \mathrm{rad} / \mathrm{s}^{2}$ \\
AIS3 & $3000 \mathrm{rad} / \mathrm{s}^{2}<\ddot{a}<3900 \mathrm{rad} / \mathrm{s}^{2}$ \\
AIS4 & $3900 \mathrm{rad} / \mathrm{s}^{2}<\ddot{a}<4500 \mathrm{rad} / \mathrm{s}^{2}$ \\
AIS5 & $4500 \mathrm{rad} / \mathrm{s}^{2}<\ddot{a}$ \\
\hline
\end{tabular}

$\ddot{a}$ : the head angular acceleration.

greater than that in the active model, which suggested that muscle activation plays a more important role in reducing the HIC of the head in a low-intensity impact. According to a study by Ommaya [36], the head angular acceleration has a definite relationship with the AIS level, as illustrated in Table 2. In our study, muscle activation seemed to be more effective in reducing the head AIS level in medium- and high-intensity impacts. Neck muscle activation reduced AIS from level 3 in the passive model to level 2 in the active model and from level 5 in the passive model to level 4 in the active model in medium- and high-speed impacts, respectively. However, in a low-speed impact, humans have a low risk of head injury, and muscle activation has few effects. Consequently, we could conclude that the activation of neck muscle could reduce head HIC, especially in a low-intensity frontal impact, but would have slightly less effect in medium- and high-intensity impacts. The neck activation system may reduce the head AIS level, especially in medium- and highintensity impacts. Considering the design of the restraint system, although the explosion time of an airbag is designed according to a test dummy without neck muscle activation, it can still efficiently protect actual human occupants from serious head injuries.

Studies have suggested that an injury of the intervertebral disc could occur due to local shear, compression, or tension forces caused by movement of the vertebral bodies $[11,37]$. In the present study, neck muscle activation showed an obvious effect in reducing intervertebral disc shear stress at almost all impact intensities, and in reducing the pressure stress at low and medium impact intensities. To date, however, there are insufficient studies to illustrate the relationship between the reduced stresses or pressures and AIS level of head injuries. The main function of the neck muscle system is to maintain the stability of the head and prevent the neck from excessive shear and pressure loads. In a low-speed impact, when a muscle activates, one component of the force is able to resist the shear load, and the other successfully reduces the axial pressure since the extension and flexion of the neck is not severe. When the impact intensity increases, the dynamic indicators become larger and the muscles must provide more force to maintain the stability of the head and prevent disc injuries due to shear stress and axial pressure. However, as the impact intensity increases, the pressure reduction due to neck activation varies from $94.4 \%$ to $11.2 \%$, and the maximum shear stress varies from $63.06 \%$ to $56 \%$, which suggests that neck activation has less protective effect. Meanwhile, it is worth noting that muscle activation in a high-intensity impact increases the stress on the upper intervertebral disc between C2 and C3. The reasons may be that the muscle activation would become larger because the severe inflexion occurring in the neck will increase with the impact intensity. Once the active force exceeds a certain value and surpasses the loads from the vertebral bodies, the intervertebral shear stress and pressure would increase concomitantly. This phenomenon obviously occurred in the upper neck in a high-speed frontal impact. The additional axial compression can reduce the shear stiffness of the cervical disc and make it easier for the shear-type soft tissue injuries to occur [29]. From the present study, we can conclude that the muscle activation behavior can prevent serious neck injuries in a low-speed frontal impact but that the risk of injury in the upper neck may be increased in a high-speed frontal impact. We are not sure whether the muscle activation behavior can raise or reduce the lower neck injuries in a high-speed frontal impact, considering the uncertain trends of shear stress and pressure between the active and passive models.

In this study, because $\mathrm{T} 1$ is defined as rigid according to the Hybrid III dummy characteristics, the connection between $\mathrm{C} 1$ and $\mathrm{T} 1$ seems to have less biofidelity in terms of the force and torque transition between the rigid and flexible parts. Another limitation of the present study is that the high impact intensity was set to $50 \mathrm{~km} / \mathrm{h}$ but a higher impact speed was not studied. This is due to the poor computational stability of the soft tissue in simulations at higher intensities.

\section{Conclusion}

The mixed dummy model has good computational efficiency and biofidelity for studying the effects of muscle activation on related head and neck injuries.

The activation of neck muscles can lower the head resultant acceleration under different impact intensities and the head angular acceleration in medium- and high-speed impacts, thereby reducing the risks of head injury.

The activation of neck muscles can also protect the neck from shear and compression injuries in a low-speed fontal impact. As the impact intensity increases, the protective effect of muscle activation on head and neck injuries is decreased. Although neck muscle activation can prevent shear stress and pressure in a medium-speed frontal impact, it may fail to prevent other types of injuries. In a high-speed frontal impact, neck muscle activation may even contribute to the risk of shear and compression injury of the upper neck.

\section{Conflicts of Interest}

The authors declare that they have no conflicts of interest.

\section{Acknowledgments}

The project was supported by the National Natural Science Foundation of China (51205117), Fondation FrancoChinoise pour la Science et ses Applications, the strategic 
emerging industry of Hunan Province and science technology research projects (2016GK4008), and the Research Foundation of the State Key Laboratory of Advanced Design and Manufacturing for Vehicle Body (51475003).

\section{References}

[1] World Health Organization, Global Status Report on Road Safety 2015, World Health Organization, 2015.

[2] A. Morris, A. Hassan, M. Mackay, and J. Hill, "Head injuries in lateral impact collisions," Accident Analysis \& Prevention, vol. 27, no. 6, pp. 749-756, 1995.

[3] D. U. Erbulut, "Biomechanics of neck injuries resulting from rear-end vehicle collisions," Turkish Neurosurgery, 2014.

[4] National Highway Traffic Safety Administration, "Traffic safety facts: occupant protection,” 2008, Data. Pub. No. DOT HS 811160 .

[5] S. Ejima, K. Ono, K. Kaneoka, and M. Fukushima, "Development and validation of the human neck muscle model under impact loading," in International IRCOBI conference, Prague (Czech Republic), 2005.

[6] B. Fréchède, N. Bertholon, J.-Y. Le Coz, F. Lavaste, and W. Skalli, "Finite element model of the human neck during omni-directional impacts: part I. Kinematics and injury," Revue Européenne des Éléments Finis, vol. 14, no. 4-5, pp. 463-485, 2005.

[7] G. P. Siegmund and J. J. R. Brault, "Role of cervical muscles during whiplash," Frontiers in Whiplash Trauma: Clinical and Biomechanical, pp. 295-320, 2000.

[8] M. Panzer, Numerical Modeling of the Human Cervical Spine in Frontal Impact, University of Waterloo, 2006.

[9] C. A. Van Ee, R. W. Nightingale, D. L. Camacho, V. C. Chancey, K. E. Knaub, E. A. Sun et al., "Tensile properties of the human muscular and ligamentous cervical spine," Stapp Car Crash Journal, vol. 44, p. 85, 2000.

[10] K. Brolin, P. Halldin, and I. Leijonhufvud, "The effect of muscle activation on neck response," Traffic Injury Prevention, vol. 6, no. 1, pp. 67-76, 2005.

[11] K. H. Yang, P. C. Begeman, M. Muser, P. Niederer, and F. Walz, "On the role of cervical facet joints in rear end impact neck injury mechanisms," SAE International Congress and Exposition, 1997.

[12] E. Choteo, "Effect of muscle activation on head-neck complex under simulated frontal car impact," in Infats Proceedings the Sixth International Forum of Automotive Traffic Safety, 2008.

[13] K. U. Schmitt, P. F. Niederer, M. H. Muser, and F. Walz, Trauma Biomechanics: Accidental Injury in Traffic and Sports, Springer, 2009.

[14] R. Jost and G. N. Nurick, "Development of a finite element model of the human neck subjected to high g-level lateral deceleration," International Journal of Crashworthiness, vol. 5, no. 3, pp. 259-270, 2000.

[15] B. Frechede, N. Bertholon, G. Saillant, F. Lavaste, and W. Skalli, "Finite element model of the human neck during omni-directional impacts. Part II: relation between cervical curvature and risk of injury," Computer Methods in Biomechanics and Biomedical Engineering, vol. 9, no. 6, pp. 379386, 2006.

[16] S. Hedenstierna, 3D Finite Element Modeling of Cervical Musculature and its Effect on Neck Injury Prevention, Teknik Och Teknologier, 2008.
[17] M. Iwamoto, Y. Kisanuki, I. Watanabe, K. Furusu, K. Miki, and J. Hasegawa, "Development of a finite element model of the total human model for safety (THUMS) and application to injury reconstruction," in Proceedings of the International IRCOBI Conference, 2002.

[18] M. Iwamoto and Y. Nakahira, A Preliminary Study to Investigate Muscular Effects for Pedestrian Kinematics and Injuries Using Active THUMS, 2014.

[19] F. S. Gayzik, D. P. Moreno, N. A. Vavalle, A. C. Rhyne, and J. D. Stitzel, "Development of the Global Human Body Models Consortium mid-sized male full body model," Injury Biomechanics Research, pp. 39-12, 2011.

[20] L. Feller, C. Kleinbach, J. Fehr, and S. Schmitt, "Incorporating muscle activation dynamics into the global human body model," in In IRCOBI Conference Proceedings, 2016.

[21] C. L. Ewing, D. J. Thomas, L. M. Patrick, G. W. J. Beeler, and M. J. Smith, "Living human dynamic response to -GX impact acceleration," Stapp Car Crash Journal, vol. 13, pp. 400-415, 1970.

[22] J. Thunnissen, J. S. H. M. Wismans, C. L. Ewing, and D. J. Thomas, "Human volunteer head-neck response in frontal flexion: a new analysis (no. 952721)," SAE Technical Paper, 1995.

[23] J. Yang and J. Yao, "Development and validation of a human neck FE model in impact loading condition," Journal of Hunan University (Natural Sciences Edition), vol. 30, no. 4, pp. 40-46, 2003.

[24] F. Li, A. Laville, D. Bonneau, S. Laporte, and W. Skalli, "Study on cervical muscle volume by means of three-dimensional reconstruction," Journal of Magnetic Resonance Imaging, vol. 39, no. 6, pp. 1411-1416, 2014.

[25] F. Li, H. Li, W. Hu, S. Su, and B. Wang, "Simulation of muscle activation with coupled nonlinear FE models," Journal of Mechanics in Medicine and Biology, vol. 16, no. 06, article 1650082, 2016.

[26] Y. Cao, F. Li, W. Hu, and S. Su, "Development and validation of a human neck muscles FE model in low-speed vehicle collisions," in 2014 Proceedings of the 11th International Forum of Automotive Traffic Safety, 2014.

[27] D. G. Krige, A Review of the Development of Geo-Statistics in South Africa, 1976.

[28] F. Li, W. Hu, S. Su, and Y. Cao, "Mixed dummy model with neck muscle force activation simulation," Journal of Automotive Safety and Energy, vol. 6, no. 3, pp. 245-249, 2014.

[29] M. J. van der Horst, "Human head neck response in frontal, lateral and rear end impact loading: modeling and validation," Knowledge \& Process Management, 2002.

[30] T. Aibe, K. Watanabe, T. Okamoto, and T. Nakamori, "Influence of occupant seating posture and size on head and chest injuries in frontal collision," in In Proceedings of the 26th Stapp Car Crash Conference, pp. 231-238, 1982.

[31] C. X. Hua, A Study of Structural Crashworthiness of Car SubFrame, Doctoral dissertation, Hunan University, 2014.

[32] F. Li, Y. Cao, S. Su, and J. Huang, "Development and validation of a neck muscle FE model for rear impact study," Journal of Hunan University, vol. 43, no. 8, pp. 45-51, 2016.

[33] C. W. Gadd, "Criteria for injury potential," Impact Acceleration Stress, vol. 977, pp. 141-145, 1962.

[34] J. Versace, "A review of the severity index (no. 710881)," SAE Technical Paper, 1971. 
[35] F. Li, H. Li, Z. Xiao et al., "A review on injury mechanism of intracerebral hemorrhage in vehicle accidents," Current Pharmaceutical Design, vol. 23, no. 15, pp. 2177-2192, 2017.

[36] OmmayaNahum, Melvis, "Biomechanics of head injury," in Biomechanics of Trauma, Appleton-Century-Crofts, Norwork, 1984.

[37] S. P. Moroney, A. B. Schultz, J. A. A. Miller, and G. B. J. Andersson, "Load-displacement properties of lower cervical spine motion segments," Journal of Biomechanics, vol. 21, no. 9, pp. 769-779, 1988. 


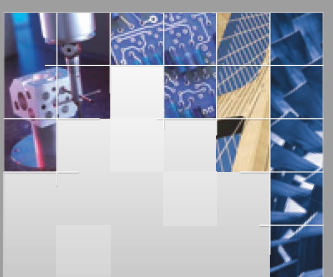

\section{Enfincering}
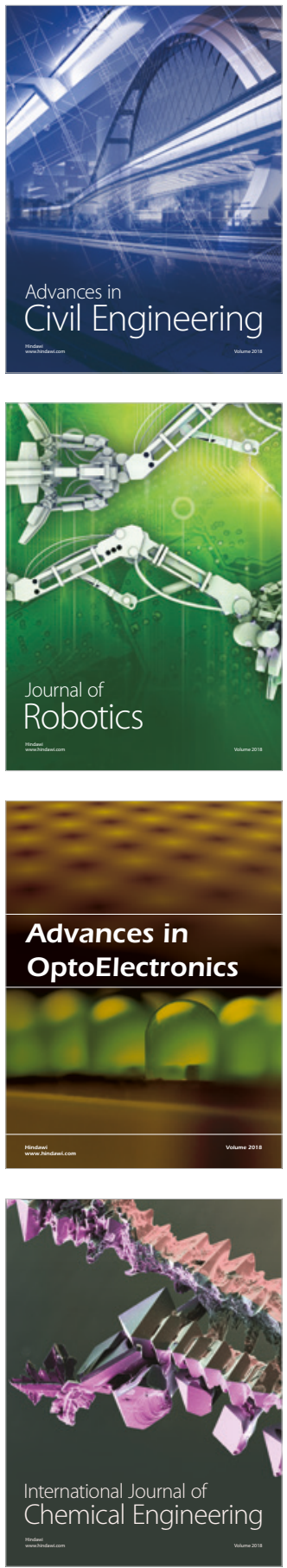

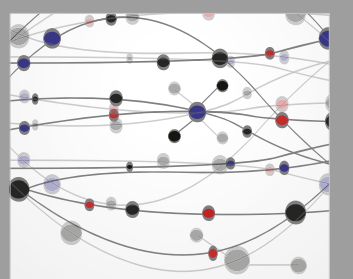

\section{Rotating \\ Machinery}

The Scientific World Journal

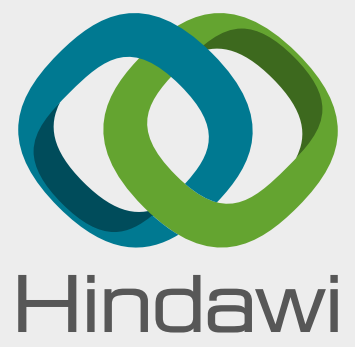

Submit your manuscripts at

www.hindawi.com
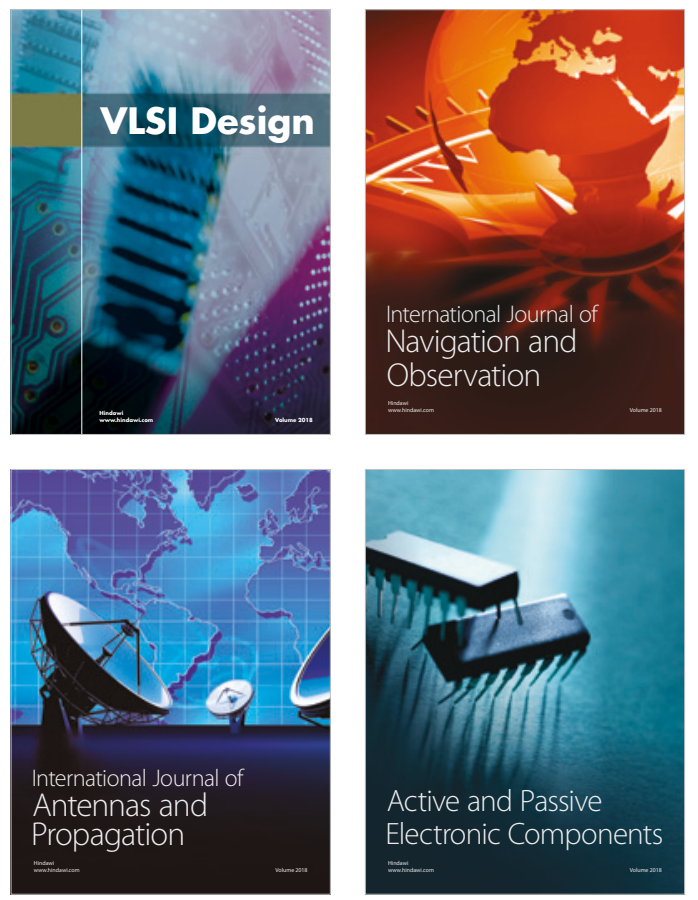
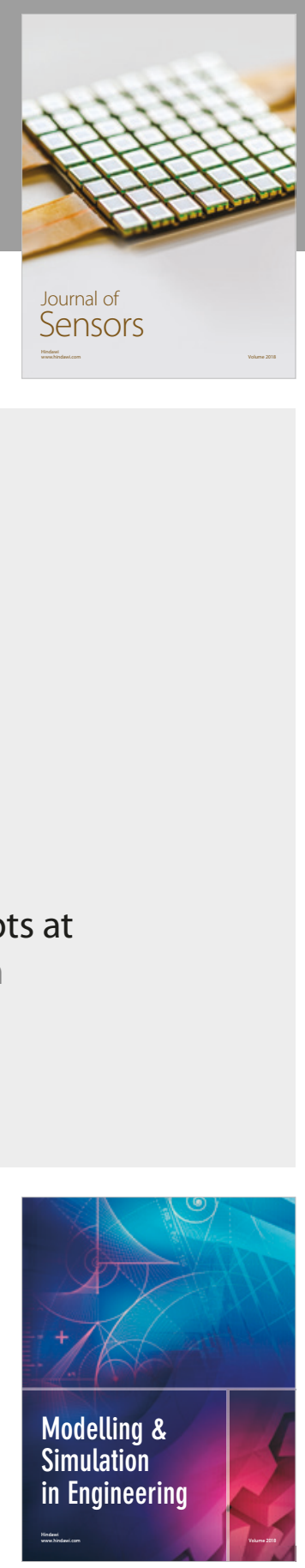

\section{Advances \\ Multimedia}
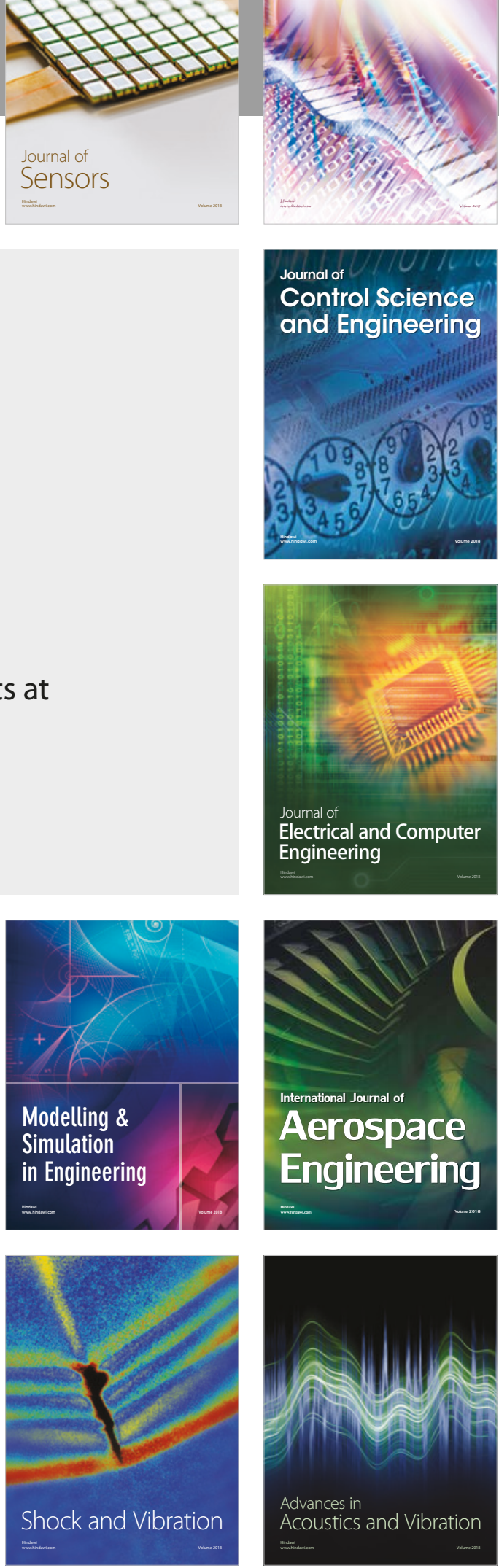